NASA Technical Memorandum 100593

\title{
CONTROL LAW PARAMETERIZATION FOR AN AEROELASTIC WIND-TUNNEL MODEL EQUIPPED WITH AN ACTIVE ROLL CONTROL SYSTEM AND COMPARISON WITH EXPERIMENT
}

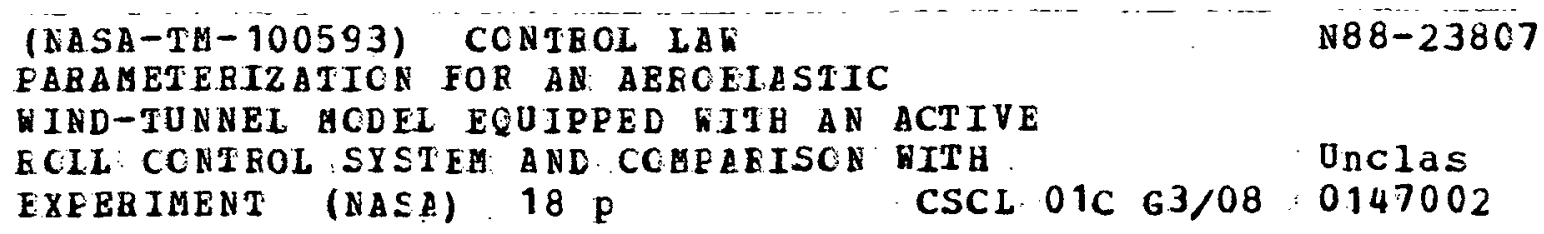

Boyd Perry III, H. J. Dunn, and Maynard C. Sandford

MAY 1988 


\title{
CONTROL LAW PARAMETERIZATION FOR AN AEROELASTIC WIND-TUNNEL MODEL EQUIPPED WITH AN ACTIVE ROLL CONTROL SYSTEM AND COMPARISON WITH EXPERIMENT
}

\author{
Boyd Perry III, H. J. Dunn, and Maynard C. Sandford \\ NASA Langley Rescarch Center \\ Hampton, Virginia 23665-5225
}

\begin{abstract}
Nominal roll control laws wcre designed, implemented, and tested on an acroelastically-scaled freeto-roll wind-tunnel model of an advanced fighter configuration. The tests were performed in the NASA Langley Transonic Dynamics Tunnel. A parametric study of the nominal roll control system was conducted. This parametric study determined possible control system gain variations which yielded identical closed-loop stability (roll mode pole location) and identical roll response but different maximum control-surface deflections. Comparison of analytical predictions with wind-tunnel results was generally very good.
\end{abstract}

\section{Nomenclature}

$$
\begin{aligned}
& \text { b wing span } \\
& C_{\text {Ip }} \text { roll-damping stability derivative }
\end{aligned}
$$

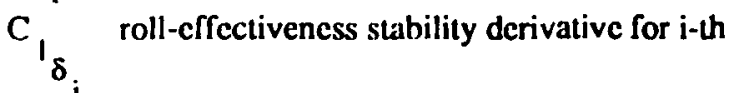

$$
\begin{aligned}
& \text { control-surface pair } \\
& \text { g. structural damping cocfficient } \\
& \mathrm{I}_{\mathrm{xx}} \text { vehicle roll moment of inertia } \\
& \mathrm{K}_{\mathrm{i}} \quad \text { foedback gain for } \mathrm{i} \text {-th loop } \\
& K_{c} \text { forward-path gain for } i \text {-th loop } \\
& \mathrm{K}_{\mathrm{c}}^{\prime} \quad \text { arbitrary value of forward-path gain } \\
& L_{p} \quad \text { rolling moment duc to roll rate, } \overline{\mathrm{q}} \mathrm{Sbl}^{*} \mathrm{C}_{1_{p}} \\
& \hat{L}_{p} \quad \text { dimensional roll damping, }-\frac{L_{p}}{I_{x x}} \\
& \mathrm{~L}_{\delta} \quad \text { rolling moment duc to deflection of } i-\text { th control } \\
& \text { surface, } \overline{\mathrm{q}} \mathrm{Sb} \mathrm{C}_{1_{\delta_{\mathrm{i}}}}
\end{aligned}
$$

\begin{tabular}{|c|c|}
\hline $\begin{array}{l}\mathrm{m} \\
\mathrm{p} \\
\mathrm{p}_{\mathrm{c}}\end{array}$ & $\begin{array}{l}\text { vehicle mass } \\
\text { roll-rate } \\
\text { roll-rate command }\end{array}$ \\
\hline$\overline{\mathbf{q}}$ & free-stream dynamic pressure, $\frac{1}{2} \rho v^{2}$ \\
\hline$S$ & wing area \\
\hline $\mathbf{s}$ & Laplace variable \\
\hline $\mathbf{s}^{\prime}$ & $\begin{array}{l}\text { arbitrary value of Laplace variable } \\
\text { b / }(2 \mathrm{~V})\end{array}$ \\
\hline $\begin{array}{l}\boldsymbol{V} \\
\delta\end{array}$ & $\begin{array}{l}\text { free-stream velocity } \\
\text { deflection of } i \text {-th control surface }\end{array}$ \\
\hline$\zeta_{n}$ & damping ratio of second-order filter \\
\hline 6 & $\begin{array}{l}\text { parameter which determines feedback gains } K_{1} \\
\text { and } K_{2}\end{array}$ \\
\hline$x$ & $\begin{array}{l}\text { parameter which determines forward-path gains } \\
\mathrm{K}_{\mathrm{c}_{1}} \text { and } \mathrm{K}_{\mathrm{c}_{2}}\end{array}$ \\
\hline & fluid density \\
\hline & roll angle \\
\hline (t) & circular frequency \\
\hline & natural frequency of second-order filter \\
\hline
\end{tabular}$$
\hat{L}_{\delta} \quad \text { dimensional roll effectiveness for } i-\text { th control- }
$$$$
\text { surface pair, } \frac{{ }_{\delta_{i}}}{I_{x x}}
$$

1 distance between center of gravity and roll axis M free-stream Mach number

\section{Abbreviations}

AFW Active Flcxible Wing

ARC Active Roll Control

cg center of gravity

dB decibel, $20 \log$ (magnitude)

LEI leading-edge-inboard surface

LEO leading-edge-outboard surface

max maximum

psf pounds per square foot

TDT Transonic Dynamics Tunnel

TEI trailing-edge-inboard surface

TEO trailing-edge-outboard surface

A dot over a quantity indicates a derivative with respect to time.

Consistent units have been used throughout the paper.

\section{Introduction}

The evolution of advanced fighters has required that the disciplines of aerodynamics, control systems, and structures be integrated into a unified aeroservoelastic 
technology which must be evaluated by sophisticated analytical methods and validated through the testing of wind-tunnel models. In support of this technology, Rockwcll International Corporation has developed a concept it refers to as the Active Flexible Wing (AFW). This concept utilizes wing flexibility and multiple active control surfaces to vary the wing shape, resulting in improved performance and reduced weight.

Under a joint Rockwcll / Air Force / NASA program, using the AFW concept, Rockwell designed and built a scaled acroelastic wind-tunnel model which has been tested twice in the NASA Langley Transonic Dynamics Tunnel (TDT). A photograph of the windtunnel model mounted in the test section of the TDT is shown in figure 1. The AFW wind-tunnel model was mounted on a sting and attached to a large bearing arrangement in such a manner that it was free to roll. NASA synthesized Active Roll Control (ARC) control laws which were tested on the model during the second TDT entry.

The purposes of this paper are to briefly describe the ARC control law design, to present and describe a NASA conducted control law parametcrization study, and to present comparisons of predicted performance and predicted robustness with wind-tunnel test results.

\section{Wind-Tunnel Model}

The wind-tunnel model is an aeroelasticallyscaled full-span model of an advanced fighter configuration. It has a fusclage and a low-aspect-ratio wing with a span of approximately 9 fect.

\section{Structure}

The model consists of a "rigid" fuselage and a "flexible" wing. The fusclage contains aluminum stringers and bulkheads and is not scaled for flexibility. The wing box contains an aluminum honeycomb core and tailored plics of graphite-cpoxy. The wing design permitted desired amounts of bending and twist as a function of acrodynamic load. The model was statically and dynamically scaled to represent a full-scale airplane with a wing span of roughly 50 feet.

For acroclastic analysis purposes, the first 10 calculated flexible antisymmetric mode shapes, frequencics, and generalized masses were provided to NASA by Rockwcll International. Table I contains the natural frequencies and descriptions of these modes. All flexible modes were assumed to have a structural damping coefficient $\mathrm{g}$ of 0.03 .

\section{Control Surfaces and Actuators}

The model has two leading-edge and two trailingedge control surfaces on each wing panel. Each control surface has a chord of 25 percent of the local wing chord and a span of 28 percent of the wing semispan. Because the wind-tunnel model was aeroelastically scaled, the roll effectiveness of each pair of surfaces varied significantly with dynamic pressure. These effectivenesses were determined experimentally during the first TDT entry of this model.

Each control surface is driven by a miniature rotary-vane electrohydraulic actuator which serves two functions: for constant inputs, it fixes the control-surface deflections relative to the wing; and for time-varying inputs, it provides control-surface motion in a manner dictated by the control law. Deflection limits are imposed on the various control surfaces to avoid exceeding actuator hinge moments and wing loads at the root.

\section{Instrumentation}

The model was instrumented with a force balance, accelerometers, strain-gage bridges, rotary variable differential transformers (RVDTs), a roll potentiometer, and a roll-rate gyro. Figure 2 contains a drawing of the model and illustrates the locations of the control surfaces and pertinent instrumentation.

\section{Wind Tunnel}

The NASA Langley Transonic Dynamics Tunnel (TDT) is a closed-circuit, continuous-flow tunnel which has a 16-ft. square test section with slots in all four walls. Mach number and dynamic pressure can be varied simultaneously, or independently, with either air or Freon as a test medium. All experimental tests of the present investigation were conducted in the TDT using a Freon test medium.

\section{Active Roll Control System}

At the time NASA was invited to participate in the AFW wind-tunnel tests the design objectives and the form (block diagram) of a roll control system, known as the Active Roll Control (ARC) System, had already been determined by Rockwell.

\section{Design Objectives} as follows:

The design objectives for the ARC system were

$$
\begin{aligned}
& \text { Robustness } \\
& 0+6 \mathrm{~dB} \text { gain margin } \\
& 0+/-45 \text { degrees phase margin } \\
& \text { Performance } \\
& 0 \text { Achieve } 90 \text { degrees roll angle in } \\
& 0.42 \text { seconds }
\end{aligned}
$$

The performance design objective is based on a scaled MIL-F-8785C (ref. 1), which specifies that the full-scale airplane be capable of rolling to 90 degrees in 1.1 seconds. 
Block Diagram

The original form of the ARC system used a roll-ratc gyro as the sensor. Rockwell's early analyses indicated that the ARC system would perform satisfactorily by using only the two most effective pairs of control surfaces at any test condition. Thus, it was necessary to include only two feedback loops and only two forward paths in the ARC system.

In anticipation of a possible need to control flexible modes with the ARC system, NASA requested a modification to the original form of the block diagram, and a second-order filter was added to the then-existing system. The analog form of this second-order filter is

$$
\frac{\omega_{n}^{2}}{s^{2}+2 \zeta_{n} \omega_{n} s+\omega_{n}^{2}}
$$

A block diagram of the final form of the ARC system, including the NASA sccond-order filter, is shown in figure 3. The block diagram includes both digital and analog elements; the dashed line in the figure separates the digital and the analog portions of the closed-loop system.

Control laws were implemented digitally with an Intcl 80286 processor and 80287 co-processor. Tustin transformations (ref. 2) were used to generate the secondorder filter in the feedback loop. The digital controller sampling rate was $200 \mathrm{Hertz}$.

\section{Design Conditions}

NASA designed nominal ARC control laws for two tunncl test conditions: a dynamic pressure of $150 \mathrm{psf}$ at a Mach number of 0.9 ; and a dynamic pressure of 250 psf also at a Mach number of 0.9. At the first condition the two most effective pairs of control surfaces were the trailing-cdge-inboard pair and the trailing-edge-outboard pair; at the sccond condition, the trailing-edge-inboard pair and the leading-cdge-outboard pair.

\section{Nominal Control Law Design}

For purposes of control law design, the acroclastic plant was represented by the rigid-body roll mode and the first 10 antisymmetric flexible modes of the acroclastic wind-lunnel model. Actuators were modeled analytically by zeroth-order-over-third-order transfer functions. The coefficients of these transfer functions wcre oblaincd using parameler estimation techniques (ref. 3) which matched both gain and phase from experimental transfer functions.

Bccause the sampling rate of the digital controller was sufficiently high compared to the natural frequencies of key flexible modes, it was assumed that the digital controller was "approximately analog" and, therefore, the nominal control law was designed using classical analog techniques. The feedback gains $\mathrm{K}_{1}$ and $\mathrm{K}_{2}$, the gains
$\mathrm{K}_{\mathrm{c}_{1}}$ and $\mathrm{K}_{\mathrm{c}_{2}}$ in the forward path, and the constants $\zeta_{\mathrm{n}}$ and $\omega_{n}$ within the second-order filter were chosen by trial and error such that the performance and robustness design objectives were met analytically.

Table II contains the results of the nominal ARC control-law design for the two test conditions. The left side of the table contains the gains and filter constants; the right side contains the predicted robustness and performance of the closed-loop system based on linear analysis (with no limits imposed on control-surface deflections). Nyquist plots (from which gain and phase margins were obtained) and time responscs (from which time-to-roll-90-degrees were obtained) were computed using the ISAC and PADLOCS codes (refs. 4 and 5) with subsonic unsteady aerodynamics computed by the method of reference 6. The full equations of motion (rigid-body roll mode plus 10 flexible modes) and the full block diagram were present in the analysis. In addition, to approximate digital-to-analog conversion, a zero-order-hold element and a computational-delay effect were added to the analysis. The input used for the predicted performance calculations was a 0.04-second ramp-hold command with a magnitude of one radian per second. This input was chosen because the magnitude was sufficiently high to produce the desired predicted performance. Performance and robustness design objectives were met at both test conditions.

Figure 4 contains two analytical Nyquist plots and illustrates (for an off-design condition) the potential effect of the second-order filicr on the robustness of the closed-loop system. The analysis conditions for figure 4 are a Mach number of 1.15 and a dynamic pressure of 250 psf. Again, the Nyquist plots wcre computed as above using the ISAC and PADLOCS codes but with supersonic unsteady aerodynamics computed by the method of reference 7. Figure 4 (a) is for no second-order filter present and shows a clockwise encirclement of the minusone point (at about 225 radians per second), corresponding to an instability of the fifth flexible mode. Figure $4(\mathrm{~b})$ is for second-order filter present (with $\zeta_{n}=0.8$ and $\omega_{n}=220$ radians per second), resulting in a very robust closed-loop system with over $10 \mathrm{~dB}$ gain margin and over 90 degrees phase margin. Comparison of the two Nyquist plots shows that stability was achieved by a 90-degree clockwise rotation and corresponding attenuation of the lobe associated with the previously unstable fifth flexible mode.

\section{Control Law Parametcrization}

\section{Background and Motivation}

The nominal ARC system has identical gains in each feedback loop and identical gains (but different from the values of the feedback gains) in each forward path. These equal values of gains result in certain closed-loop stability, certain closed-loop roll performance, and 
(neglecting the effects of different actuator transfer functions) equal commanded control-surface deflections for the two pairs of surfaces involved.

It was recognized (after making some simplifying assumptions) that there are an infinitc number of combinations of fecdback gains $\left(\mathrm{K}_{1}\right.$ different from $\left.\mathrm{K}_{2}\right)$ and an infinite number of combinations of forward-path gains ( $\mathrm{K}_{\mathrm{c}_{1}}$ different from $\mathrm{K}_{\mathrm{c}_{2}}$ ) which result in the same closed-loop stability and closed-loop roll performance but different commanded control-surface deflections for the surfaces involved. The consequence of this is that the deflections of one pair of surfaces may be "traded off" against the deflections of the other pair with no change (loss or gain) of either stability or performance.

With an cye toward actual airplane design, this trade off has beneficial implications in terms of wing loads, actuator sizing, and the ability of one pair of control surfaces to be used for multiple active control functions simultancously.

\section{Development of Parametric Study}

The control law parameterization study was developed using the following guidelines.

Fcedback gains $\mathrm{K}_{1}$ and $\mathrm{K}_{2}$ vary simultaneously (in gencral, $K_{1}$ different from $K_{2}$ ) such that each is uniquely determined by a single parameter, $\boldsymbol{K}$. Parameter $\mathrm{K}$ and gains $K_{1}$ and $K_{2}$ are continuously variable and any value of $K$ (and, therefore, the corresponding unique pair of gains $K_{1}$ and $K_{2}$ ) results in the same closed-loop stability as any other value of $k$. The relationship between parameter $\kappa$ and gains $K_{1}$ and $K_{2}$ is described below in the subscction entitled "Constant Closed-Loop Stability."

$\begin{array}{rlll}\text { Forward-path gains } K_{c_{1}} \text { and } K_{c_{2}} & \text { vary } \\ \text { simultancously (in general, } K_{c_{1}} \text { different from } & K_{c_{2}} \text { ) }\end{array}$ such that cach is uniquely detcrmincd by another single parameter, $\kappa_{c}$. Parameter $\kappa_{c}$ and gains $K_{c_{1}}$ and $K_{c_{2}}$ are also continuously variable. For a given $\kappa$ and for a given roll-rate command, any value of $\kappa_{c}$ (and, therefore, the corresponding unique pair of gains $K_{c_{1}}$ and $K_{c_{2}}$ ) results in the same closed-loop roll performance as any other value of $\kappa_{c}$. The relationship between parameter $\kappa_{c}$ and gains $K_{c_{1}}$ and $K_{c_{2}}$ is described below in the subscction entitled "Constant Closed-Loop Roll Performance."

\section{Choice of Stability and Performance}

For the purpose of this control law parameterization study the stated ARC robustness and performance design objectives ccase to be important. It is required to show only that any desired robustness (stability) and any desired performance may be held constant for many values of $\mathrm{K}$ and for many values of $\kappa_{\mathrm{c}}$. For convenience, the following stability and performance criteria were chosen for the parametric study:

Stability

0 Closed-loop roll-mode eigenvalue located at $s=-26$ on the negative real axis of the complex plane. Gain and phase margins not

Performance specified.

0 Achieve 90 degrees roll angle in 1.5 seconds.

The chosen stability represents a desired location of the roll-mode eigenvalue and has been scaled from the desired location for a full-scale airplane. The roll-rate command chosen to achieve this more conservative performance is a 0.3 -second ramp-hold command of the necessary magnitude. This command was chosen because it is a gradual, low-amplitude command which neither saturates the control surfaces nor excites flexible modes.

\section{Example Condition}

Whenever numerical examples are required to illustrate the control law parameterization, the following test condition, referred to as the "example condition," is used: Mach number of 0.9 ; dynamic pressure of $250 \mathrm{psf}$. At the example condition the two most effective pairs of surfaces are the TEI and the LEO. To keep the illustrations general, the TEI surface is identified as Surface 1; the LEO surface as Surface 2.

\section{Problem Simplification}

The following approximations were made in order to simplify the mathematics while at the same time retaining the essential elements of control law parameterization:

(1) From the ARC block diagram in figure 3, only the gains were retained. The following clements were neglected: stick-shaping filter, anti-aliasing filter, second-order filter, and actuator transfer functions.

(2) From the aeroclastic plant, only the rigidbody roll mode was retained. All flexible modes were neglected.

(3) The center of gravity of the wind-tunnel model was assumed to lie on the roll axis.

Approximation (1) assumes that the neglected transfer functions are closely approximated by unity gain and zero phase over the frequency range of interest. The resulting simplified block diagram is shown in figure 5. 
Approximation (2) deals with the aeroelastic plant (open-loop wind-tunnel model) only and assumes that the dynamics of the acroelastic plant are closely approximated by the dynamics of the rigid-body roll mode. This approximation is valid if the frequency content of the commanded input is well below the frequency of the first flexible mode such that the flexible modes are not excited.

The rigid-body roll cquation for the open-loop wind-lumel model is based on cquation $4.15,8(\mathrm{~b})$ in reference 8 and is given by

$$
I_{x x} \ddot{\phi}-\Phi b t^{0} c_{l_{p}} \dot{\phi}+m g l \sin \phi=\Phi b C_{I_{\delta}} \delta_{1}+\Phi b C_{\delta_{\delta}} \delta_{2}
$$

Equation (1) differs in two ways from the cquation in reference 8: control-surface rate derivatives have been neglected and the quantity $\mathrm{mgl} \sin \phi$ has been added. This quantity is referred to as the "cg-offset term" and is present because the center of gravity of the windtunnel model is a distance 1 below the roll axis of the model. The cg-offset term causes equation (1) to be nonlincar. The cquation may be lincarized by utilizing the small-angle approximation (substituting $\phi$ for $\sin \phi$ ), resulting in the following

$$
I_{x x} \ddot{\phi}-\Phi b t^{*} C_{1} \dot{\phi}+m g l \phi=\bar{\phi} b C_{\delta_{\delta_{1}}} \delta_{1}+\Phi b C_{1_{\delta_{2}}} \delta_{2}
$$

Approximation (3) assumes that the roll axis of the wind-tunnel model passes through its center of gravity (i.e., that the distance 1 is zcro) as it would on an actual airplane. This approximation results in the following rigid-body roll cquation

$$
I_{x x} \ddot{\phi}-\bar{q} S b t^{*} C_{1} \dot{\phi}=\bar{q} S b C_{\delta_{1}} \delta_{1}+\bar{q} S b C_{1_{\delta}} \delta_{2}
$$

This assumption permits the derivation of control-law parameterization to proceed in a manner consistent with airplane equations of motion rather than in a manner consistent with wind-tunnel equations of motion. In a subsequent section of this paper showing comparisons of analytical predictions and experimental results the cg-offset term will be added back into the analysis, as in cquation (2).

\section{Constant Closed-Loop Stability}

Referring to the simplified block diagram in figure 5 and to equation (3) and recognizing that $p=\phi$, the following closed-loop transfer function is obtained

$$
\frac{p(s)}{p_{c}(s)}=\frac{K_{c} \hat{\mathrm{L}}_{\delta_{1}}+\mathrm{K}_{c_{2}} \hat{\mathrm{L}}_{\delta_{2}}}{s+\hat{\mathrm{L}}_{p}+\mathrm{K}_{1} \hat{\mathrm{L}}_{\delta_{1}}+\mathrm{K}_{2} \hat{\mathrm{L}}_{\delta_{2}}}
$$

The quantities $\hat{\mathrm{L}}_{p}, \quad \hat{\mathrm{L}}_{\delta_{1}}$, and $\hat{\mathrm{L}}_{\delta_{2}}$ are constant at a given wind-tunnel test condition. Closedloop stability may be deduced from the denominator of equation (4). For constant closed-loop stability (pole location) the quantity

$$
\hat{\mathrm{L}}_{p}+\mathrm{K}_{1} \hat{\mathrm{L}}_{\delta_{1}}+\mathrm{K}_{2} \hat{\mathrm{L}}_{\delta_{2}}
$$

must be constant, with valuc, say, s' (where, from an carlier section, $s^{\prime}=26$ ). The closed-loop eigenvalue will, therefore, be located at $s=-s^{\prime}$ on the negative real axis in the complex plane. By inspection, the following linear equation may be written for $K_{2}$ as a function of $K_{1}$ and results in this constant closed-loop stability

$$
\mathrm{K}_{2}=\frac{\mathrm{s}^{\prime}-\hat{\mathrm{L}}_{\mathrm{p}}}{\hat{\mathrm{L}}_{\delta_{2}}}-\frac{\hat{\mathrm{L}}_{\delta_{1}}}{\hat{\mathrm{L}}_{\delta_{2}}} \mathrm{~K}_{1}
$$

All combinations of $\mathrm{K}_{1}$ and $\mathrm{K}_{2}$ which satisfy cquation (5) result in a closed-loop system whose eigenvalue is located at $s=-s^{\prime}$.

Figure 6 contains a plot of $\mathrm{K}_{2}$ as a function of $K_{1}$ and illustrates the correspondence between these gains and parameter $\mathrm{K}$. The plot is a straight line lying in the sccond, third, and fourth quadrants of the $K_{1}-K_{2}$ plane.

The line has a slope of $-\frac{\hat{\mathrm{L}}_{\delta_{1}}}{\hat{\mathrm{L}}_{\delta_{2}}}$, a $\mathrm{K}_{1}$-intercept of $\frac{s^{\prime}-\hat{L}_{p}}{\hat{L}_{\delta}}$, and a $K_{2}$-intercept of $\frac{s^{\prime}-\hat{L}_{p}}{\hat{L}_{\delta_{2}}}$. For the portion of the line in the third quadrant, parameter $K$ varies linearly, as shown in the figure, with values between zero and one. The following expressions define gains $K_{1}$ and $\mathrm{K}_{2}$ as functions of parameter $\kappa$

$$
K_{1}=\frac{s^{\prime}-\hat{L}_{p}}{\hat{L}_{\delta_{1}}} K
$$




$$
K_{2}=\frac{s^{\prime}-\hat{L}_{p}}{\hat{L}_{\delta_{2}}}(1-\kappa)
$$

When $K$ is equal to zcro, gain $K_{1}$ is zero (Loop 1 is open) and gain $K_{2}$ alone is "holding" the closed-loop cigenvalue at $s=-s^{\prime}$. Values of $x$ less than zero (values of $\mathrm{K}_{1}$ greater than zero) corresponds to a stable closed-loop system in which Loop 1, by itself, is unstable.

When $K$ is equal to one, gain $K_{2}$ is zero (Loop 2 is open) and gain $K_{1}$ alone is "holding" the closed-loop cigenvalue at $s=-s$ '. Values of $K$ greater than one (values of $\mathrm{K}_{2}$ greater than zero) corresponds to a stable closedloop system in which Loop 2, by itself, is unstable.

The dashed line in figure 6 represents $K_{2}=K_{1}$. The point of intersection of the dashed line with the solid line yields the value of $K(=0.76$ for the example condition) which corresponds to equal values of fecdback gain.

Figure 7 contains on the left, the closed-loop cigenvalue in the complex plane and on the right, a Nyquist plot with the loop broken at the plant output. For these plots $\kappa=0.76$, but control law parameterization guarantees that for any $K$ the closed-loop eigenvalue and the Nyquist plot will be identical to those in figure 7.

\section{Censtani Closed-Loop Roll Pcrformance}

For present purposes, "roll performance" is understood to be roll angle and roll rate as functions of time. Assuming a given roll-rate command and assuming having fixed the denominator of equation (4) by the method of the previous section, constant closed-loop roll performance may be obtained by fixing the numerator of cquation (4) in a similar manner. If the value of the numerator is arbitrarily set to the value which results when $K_{c_{1}}$ and $K_{c_{2}}$ are both equal to $K_{c}{ }^{\prime}$, the following lincar cquation, for $\mathrm{K}_{\mathrm{c}_{2}}$ as a function of $\mathrm{K}_{\mathrm{c}_{1}}$, may be written

$$
K_{c_{2}}=\frac{K_{c}^{\prime}\left(\hat{\mathrm{L}}_{\delta_{1}}+\hat{\mathrm{L}}_{\delta_{2}}\right)}{\hat{\mathrm{L}}_{\delta_{2}}}-\frac{\hat{\mathrm{L}}_{\delta_{1}}}{\hat{\mathrm{L}}_{\delta_{2}}} \mathrm{~K}_{\mathrm{c}_{1}}
$$

All combinations of $\mathrm{K}_{\mathrm{c}_{1}}$ and $\mathrm{K}_{\mathrm{c}_{2}}$ which satisfy cquation (8) result in a closed-loop system whose closedloop roll performance is constant.
Figure 8 contains a plot of $\mathrm{K}_{\mathrm{c}_{2}}$ as a function of $\mathrm{K}_{\mathrm{c}_{1}}$ and illustrates the correspondence between these gains and parameter $\kappa_{c}$. The plot is a straight line lying in the first, second, and fourth quadrants of the $K_{c_{1}}$ $\mathrm{K}_{\mathrm{c}_{2}}$ plane. The line has a slope of $-\frac{\hat{\mathrm{L}}_{\delta_{1}}}{\hat{\mathrm{L}}_{\delta_{2}}}$, a $\mathrm{K}_{\mathrm{c}_{1}}$ intercept of $\frac{\mathrm{K}^{\prime}\left(\hat{\mathrm{L}}_{\delta_{1}}+\hat{\mathrm{L}}_{\delta_{2}}\right)}{\hat{\mathrm{L}}_{\delta_{1}}}$, and a $\mathrm{K}_{c_{2}}$-intercept of $\frac{\mathrm{K}_{c} c\left(\hat{\mathrm{L}}_{\delta_{1}}+\hat{\mathrm{L}}_{\delta_{2}}\right)}{\hat{\mathrm{L}}_{\delta_{2}}}$. For the portion of the line in the first quadrant parameter $\kappa_{c}$ varies linearly, as shown, with values between zero and one. The following expressions define gains $K_{c_{1}}$ and $K_{c_{2}}$ as functions of parameter $K_{c}$

$$
\mathrm{K}_{c_{1}}=\frac{\mathrm{K}_{c}^{\prime}\left(\hat{\mathrm{L}}_{\delta_{1}}+\hat{\mathrm{L}}_{\delta_{2}}\right)}{\hat{\mathrm{L}}_{\delta_{1}}} \mathbf{K}_{\mathrm{c}}
$$

$$
K_{c_{2}}=\frac{K_{c}^{\prime}\left(\hat{\mathrm{L}}_{\delta_{1}}+\hat{\mathrm{L}}_{\delta_{2}}\right)}{\hat{\mathrm{L}}_{\delta_{2}}}\left(1-K_{\mathrm{c}}\right)
$$

When $\kappa_{c}$ is equal to zero, gain $K_{c_{1}}$ is zero; when $\kappa_{c}$ is equal to one, gain $K_{c_{2}}$ is zero. The dashed line represents $\mathrm{K}_{\mathrm{c}_{2}}=\mathrm{K}_{\mathrm{c}_{1}}$, and the point of intersection of the dashed line with the solid line yields the value of $\kappa_{c}(=0.76$ for the example condition) which corresponds to equal values of gain in the forward path.

Figure 9 contains analytical plots of the 0.3second ramp-hold command and the resulting roll-angle and roll-rate responses for $k=0.76$ and $\kappa_{c}=0.76$. The magnitude of the command was chosen such that a roll angle of 90 degrees is achieved at time 1.5 seconds. These time histories were obtained by applying the command to the closed-loop system represented by the simplified block diagram in figure 5. For these plots $\kappa=0.76$ and $\kappa_{c}=$ 
0.76 , but control law parametcrization guarantees that for any $\kappa$ and for any $\kappa_{c}$ the roll-angle and roll-rate responses will be identical to those in figure 9.

\section{Control-Surface Deflections as Functions of $k$ and $x_{c}$}

Control-surface-deflection time histories vary as functions of parameters $k$ and $K_{c}$. Figure 10 contains time histories of Surface 2 deflecting in response to the 0.3second roll-rate command for threc values of $k$ (at $\kappa_{c}=$ 0.76). The maximum (absolute) value of each of these time histories is indicated on the plots with open circles. Figurc 11 contains time histories of Surface 2 deflecting in response to the 0.3 -second roll-rate command for three values of $x_{c}$ (at $x=0.76$ ). The maximum (absolute) value of each of these time histories is indicated with closed circles. It can be seen from figures 10 and 11 that the character and magnitude of the deflection time histories can change significantly as $\mathrm{K}$ and $\mathrm{K}_{\mathrm{c}}$ vary.

It can be cumbersome and confusing to try to understand the variation of entire time histories with respect to even one parameter. A better approach would be to try to understand the variation of a single quantity related to each time history. Such an approach is taken hcrc. The measure of how these time histories vary is the absolute valuc of the maximum deflection obtained in response to the 0.3-second roll-rate command. This section presents the variation of these maximum deflections for values of $\boldsymbol{\kappa}$ between zero and one and for values of $\kappa_{c}$ between zero and one.

Figure 12(a) contains an analytically-predicted contour plot of the maximum values of Surface 1 deflection $\left.\left(\delta_{1}\right)_{\max }\right)$ as functions of $\kappa$ and $\kappa_{c}$. It was obtained by sampling many time histories of $\delta_{1}$ as $K$ and $\kappa_{c}$ were varied. Parameters $\kappa$ and $\kappa_{c}$ were each varied from 0.00 to 1.00 in increments of 0.05 , for a total of 441 combinations of $\kappa$ and $\kappa_{c}$. The plot is a "valley" with the locus of minima running diagonally. The contour interval is 1 degree. The minimum point on the plot is zero and occurs in the lower left corner (at $k=K_{c}=0$ ), which corresponds to $K_{1}=K_{c_{1}}=0$. From the simplified block diagram in figure $5, K_{1}=K_{c_{1}}=0$ means that Surface 1 receives no signals to deflect: none from the roll-rate command; none from the roll-rate feedback. The deflection of Surface 1 is therefore zero and Surface 2 does all the work.

Figure 12(b) contains an analytically-predicted contour plot of the maximum values of Surface 2 deflection ( $\delta_{2}$ max )as functions of $k$ and $\kappa_{c}$. The plot is also a "valley" with the locus of minima running diagonally. Again, the contour interval is 1 degree. The open and closed circles correspond to those from figures 10 and 11. The minimum point on the plot is zero and occurs in the upper right corner (at $k=\kappa_{c}=1$ ), which corresponds to $K_{2}=K_{c_{2}}=0$. From the simplified block diagram in figure $5, \mathrm{~K}_{2}=\mathrm{K}_{\mathrm{c}_{2}}=0$ means that Surface 2 receives no signals to deflect: none from the roll-rate command; none from the roll-rate fecdback. The deflection of Surface 2 is therefore zero and Surface 1 does all the work.

\section{Trading Off Control-Surface Deflections Against Each Other}

By proper choice of the parameters $k$ and $x_{c}$ the maximum deflection of one control surface may be traded off against the maximum deflection of the other. As an illustration, figure 13 contains plots of $\delta_{1}$ max $\delta_{2 \max }$ as functions of $\kappa_{\text {, for }} \kappa_{c}=0.76$. The curves in figure 13 correspond to taking "slices" (at this value of $\kappa_{c}$ ) through the contour plots in figures 12 (a) and 12(b). In figure 13, deflection $\delta_{2}$ max reaches a minimum value at $K=0.62$, which corresponds to a point at the bottom of the "valley" of figure 12(b). In figure 13, however, deflection $\delta_{1}$ decreases over the entire $k$ range without reaching a minimum. (It can be seen from figure 12(a) that, at this value of $\kappa_{c}$, the bottom of the "valley" occurs at a value of $K$ greater than one.) From figure 13 it can been seen that $\delta_{1}$ ax ${ }^{\text {and } \delta_{2}}$ are equal at two values of $\kappa$. In the range of $\kappa$ between the two values, $\delta_{2_{\text {max }}}$ is less than $\delta_{1_{\text {max }}}$; outside this range of $k$, $\delta_{2}$ is greater than $\delta_{1}$ max . At $k=0.76$, not only are the maximum values equal, but the entire time histories are identical.

Thus, if it were neccssary (because of, say, the resulting reductions of wing loads) to minimize the maximum deflection of Surface 2 (whilc at the same time maintaining stability and performance constant), the control law parameterization provides the value of $\kappa$ (and, therefore, the gain combination, $\mathrm{K}_{1}$ and $\mathrm{K}_{2}$ ) necessary to accomplish this task. 
Wind-Tunnel Results and Comparison with Analysis

Erequency-Response Test Technique

Nyquist frequency-response plots were obtained experimentally with the wings level and with the windlunnel model free to roll. In the ARC system the reedback path was broken at the plant output and an analog sinusoidal signal (whose frequency varied logarithmically between 2 and $20 \mathrm{Hertz}$ over a span of about two minutes) was inserted at the break. This signal and the analog output signal from the roll-rate gyro were recorded and later processed by an HP-5420 signal analyzer, yielding the experimental Nyquist plots.

Deflection limits were imposed on the control surfaces at all times. Because of this imposition, care was taken to insure that the magnitude of the input sinusoidal signal was small enough so that the control surfaces would never saturate at any time during the Nyquist tests.

\section{Time-Response Test Technique}

Commanded roll mancuvers were performed using the digital control computer. The wind-tunnel model was initially held in place with the left wing $\mathbf{4 5}$ degrces down by a roll-trim system also residing in the digital computer. At the initiation of the maneuver the computer disengaged the roll-trim system and engaged the roll-control system. Referring to the block diagram in figurc 3, the computer then generated the 0.3-second ramphold roll-rate command signal. This signal passed through the stick-shaping filter and forward-path gains through the digital-to-analog converters and into the actuators. In response to the deflecting control surfaces, the model rolled through the wings-level position to a position with the left wing 45 degrees up, for a total incremental roll angle of 90 degrees. At this point the computer terminated the maneuver by re-engaging the rolltrim system to hold the model in the left-wing-up position.

The 45-degree start and stop positions were chosen because of the small angle approximation made in the cg-offset term of the rigid-body roll equation (eq. 2). The difference between $\phi$ and $\sin \phi$ is only about 10 percent when $\phi$ is 45 degrees, and this difference approaches z.cro as $\phi$ approaches zero. Thus, this choice of start and stop positions minimizes the crror incurred because of the approximation.

\section{Correclion to Expcrimental Data}

About midway through the threc-week windtunnel test, it was determined from comparison of integrated roll rate with roll-angle measurement that the roll rate gyro output was 25 percent too high. At that time, and for all subsequent runs, a factor of 0.8 was applicd to the output of the roll-rate gyro to account for the discrepancy. All experimental data at the first test condition (M $=0.9, q=150 p s f)$ was obtained before the
0.8 factor was applied to the output of the gyro. All experimental data at the second test condition $(\mathrm{M}=0.9, \mathrm{q}$ $=250 \mathrm{psf}$ ) was obtained after the 0.8 factor was applied to the output of the gyro. Therefore, for consistency in comparing wind-tunnel data with analysis, any comparisons at the first test condition have been rescaled to include the 0.8 factor.

\section{Nominal Control Law}

Figure 14 contains a comparison of analytical and experimental Nyquist plots for the nominal ARC control law at a Mach number of 0.9 and a dynamic pressure of $150 \mathrm{psf}$. The analytical Nyquist plot was obtained using, again, the ISAC and PADLOCS codes with the full equations of motion (rigid-body roll mode plus ten flexible modes) and with the full block diagram (all filters as well as the zero-order-hold element and the computational-delay effect) present in the analysis. The $\mathrm{cg}$-offset term was not present in the analysis. The experimental Nyquist plot was obtained in the manner described above. It can be seen from figure 14 that the analysis correctly predicted the general shape of the plot as well as the relationships between the first two flexible modes. The analysis predicted the phase margin well but was unconservative (by about $3 \mathrm{~dB}$ ) in its prediction of the gain margin.

Table III contains a summary of the analytical and experimental gain and phase margins for both test conditions. The gain-margin design objective was met at one test condition; the phase-margin design objective was met at both.

\section{Control Law Parametcrization}

From an earlier section of this paper the control law parameterization was constructed to yield identical Nyquist plots for all values of $K$. Because the derivation of control law parameterization was based on a singledegree-of-freedom system this requirement holds for a single-degree-of-freedom system. However, for a manydegree-of-freedom system (such as the AFW wind-tunnel model), which is closely approximated (at low frequencies) by a single-degree-of-freedom system, the requirement should hold only approximately.

To investigate the validity of the parameterization Nyquist plots were obtained analytically and experimentally for several values of $\boldsymbol{\kappa}$ between zero and one, and gain margins and phase margins were taken from the plots. The analytical Nyquist plots were, again, obtained with the full equations of motion and with the full block diagram present in the analysis.

Figure 15 contains a comparison of analytical and experimental gain and phase margins as a function of parameter $K$ at a Mach number of 0.9 and a dynamic pressure of $150 \mathrm{psf}$. It can be seen from the figure that analytical gain and phase margins and experimental gain and phase margins are approximately constant as a 
function of parameter $\kappa$. Gain margins only vary by about $+/-1 \mathrm{~dB}$; phase margins vary by about $+/-5$ degrecs. (Although not shown, the Nyquist plots are also approximately constant as a function of parameter $K$.) This trend verifies the control law parameterization.

To investigate the trading off of control surface deflections as predicted by the control law parameterization, time responses were obtained analytically and experimentally for several values of $K$ and $\kappa_{c}$ between zero and one. The analytical time responses wcre obtained with the rigid-body roll-mode approximation to the full cquations of motion (cg-offset term present -- cq. (2)) and with the simplificd block diagram (fig. 6). The roll-rate command, analytically and experimentally, was the 0.3 -second ramp-hold signal with the same magnitude.

Figure 16(a) contains a comparison of maximum (absolutc) valucs of deflections $\delta_{1}$ (TEI) and $\delta_{2}$ (LEO) as a function of $\kappa$ (for $\kappa_{c}=0.76$ ) at a Mach number of 0.9 and a dynamic pressure of $250 \mathrm{psf}$; figure 16 (b) contains a similar comparison as a function of $\boldsymbol{k}_{\mathrm{c}}$ (for $\mathrm{K}=0.76$ ). The solid and dashed lines correspond to the analytical predictions of $\delta_{1}$, and $\delta_{2}$ max , respectively; the open and closed symbols correspond to the experimental results. From figure 16 it can be seen that the analysis correctly predicts the behavior of $\delta_{1_{\max }}$ and $\delta_{2_{\max }}$ as functions of $K$ and $\kappa_{c}$, and, therefore, verifies the tradc-off predicted by the control law parameterization.

\section{Concluding Remarks}

This paper (1) outlines the design and implementation of nominal control laws for active roll control, (2) describes a control law parameterization study, and (3) presents a comparison of wind-tunnel results and analytical predictions for an aeroelastically-scaled windtunnel model of an advanced fighter configuration. The model was frec to roll and was tested in the NASA Langley Transonic Dynamics Tunnel. The nominal control laws met the gain-margin design objective $(+6$ $\mathrm{dB}$ ) at one test condition and met the phase-margin design objective ( $+/-45$ degrees) at both test conditions. Comparison of analytical predictions with wind-tunnel results was gencrally very good and verified both the robustness and the performance requirements for the control law parametcrization study.

\section{Acknowledgement}

The authors wish to acknowledge the work of Dr.Vivck Mukhopadhyay of the Aerospace Technologies Division of PRC Kentron, Hampton, Virginia, for his efforts in the design of the nominal ARC control laws.

\section{References}

${ }^{1}$ Anon: "Military Specification. Flying Qualities of Piloted Airplanes. MIL-F-8785C.

${ }^{2}$ Franklin, Gene F.; and Powell, J. David: Digital Control of Dynamic Systems. Addison-Wesley Publishing Company, Reading, Massachusettș, 1981.

${ }^{3}$ Seidel, Robert C.: Transfer Function Parameter Estimation from Frequency Response Data - A Fortran Program. NASA TM X-3286, September, 1975.

${ }^{4}$ Peele, E. L.; and Adams, W. M., Jr.: A Digital Program for Calculating the Interaction Between-Flexible Structures, Unsteady Aerodynamics, and Active Controls. NASA TM-80040, 1979.

5 Newsom, J. R.; Adams, W. M., Jr.; Mukhopadhyay, V.; Tiffany, S. H.; and Abel, I.: Active Controls: A Look at Analytical Methods and Associated Tools. NASA TM-86269, July, 1984.

${ }^{6}$ Geising, J. P.; Kalman, T. P.; and Rodden, W. P.: Subsonic Unsteady Aerodynamics for General Configurations, Part I: Direct Application of the Nonplanar Doublet Lattice Method. AFFDL-TR-71-5, 1971.

${ }^{7}$ Clever, W:: Subsonic / Supersonic Linear Unsteady Aerodynamics. AIAA Paper No. 85-4059-CP. Presented at AIAA 3rd Applied Aerodynamics Conference, Colorado Springs, Colorado, October 14-16, 1985.

${ }^{8}$ Etkin, Bernard: Dynamics of Flight. John Wiley and Sons, Inc., New York, 1959. 
Table I. - Structural Modes of Wind-Tunnel Model

\begin{tabular}{|c|l|c|}
\hline Mode & Description & Frequency, $\mathrm{Hz}$ \\
\hline 1 & Sting 1st bending & 7.18 \\
2 & Wing 1st bending & 12.83 \\
3 & Fuselage yaw & 16.60 \\
4 & Wing 2nd bending & 34.17 \\
5 & Wing 1st torsion & 35.05 \\
6 & Wing/fuselage & 38.59 \\
7 & Wing 3rd bending & 47.96 \\
8 & Wing bending/torsion & 51.10 \\
9 & Wing 2nd torsion & 53.03 \\
10 & Wing/fuselage & 56.99 \\
\hline
\end{tabular}

Table II. - Nominal Control Laws for Active Roll Control System Mach $=0.9$

\begin{tabular}{|c|c|c|c|c|c|c|c|c|c|}
\hline \multirow{2}{*}{$\begin{array}{c}\bar{q} \\
\text { (psf) }\end{array}$} & \multirow{2}{*}{$k_{1}$} & \multirow{2}{*}{$K_{2}$} & \multirow{2}{*}{$\zeta$} & \multirow{2}{*}{$\left(\begin{array}{c}\omega_{n} \\
\left(\frac{\text { rad }}{8 \otimes c}\right)\end{array}\right.$} & \multicolumn{2}{|c|}{ Gain margin } & \multicolumn{2}{|c|}{ Phase margin } & \multirow{2}{*}{$\begin{array}{l}\text { Time } \\
\text { to } 90 \\
\text { (sec) }\end{array}$} \\
\hline & & & & & dB & $\begin{array}{l}\text { @ } \omega \\
\left(\frac{\mathrm{rad}}{\mathrm{sec}}\right)\end{array}$ & Deg & $\begin{array}{l}@ \omega \\
\text { @ird } \\
\text { (rad } \\
\text { sect }\end{array}$ & \\
\hline 150 & $\begin{array}{l}0.2 \\
\text { (TEI) }\end{array}$ & $\begin{array}{l}0.2 \\
\text { (TEOO) }\end{array}$ & 0.8 & 220 & 8.3 & 60 & 72 & 21 & 0.28 \\
\hline 250 & $\begin{array}{l}0.2 \\
\text { (TEI) }\end{array}$ & (LEO) & 0.8 & 220 & 9.4 & 63 & 76 & 23 & 0.30 \\
\hline
\end{tabular}

Table III. - Comparison of Robustness Characteristics for Nominal Control Laws

\begin{tabular}{|c|c|c|c|c|c|c|c|c|}
\hline \multirow{3}{*}{$\begin{array}{c}\text { Dynamic } \\
\text { pressure, } \\
\text { psf }\end{array}$} & \multicolumn{4}{|c|}{ Gain margins } & \multicolumn{4}{|c|}{ Phase margins } \\
\hline & \multicolumn{2}{|c|}{ Analysis } & \multicolumn{2}{|c|}{ Experiment } & \multicolumn{2}{|c|}{ Analysis } & \multicolumn{2}{|c|}{ Experiment } \\
\hline & $d B$ & $\begin{array}{l}\text { @ }) \\
\left(\frac{\mathrm{rad}}{\mathrm{sec}}\right)\end{array}$ & dB & 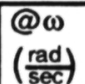 & Deg. & $\begin{array}{l}@ \omega \\
\left(\frac{\mathrm{rad}}{\mathrm{sec}}\right)\end{array}$ & Deg. & 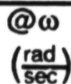 \\
\hline 150 & 8.3 & 60 & 5.4 & 57 & 72 & 21 & 68 & 25 \\
\hline 250 & 9.4 & 63 & 6.5 & 55 & 76 & 23 & 63 & 25 \\
\hline
\end{tabular}

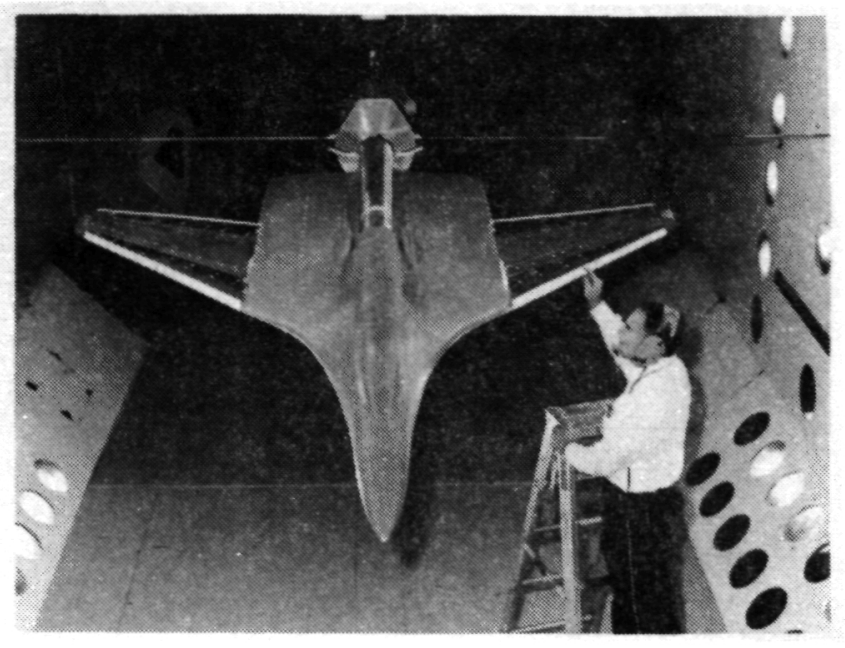

Figure 1. - AFW wind-tunnel model in NASA Langley Transonic Dynamics Tunnel.

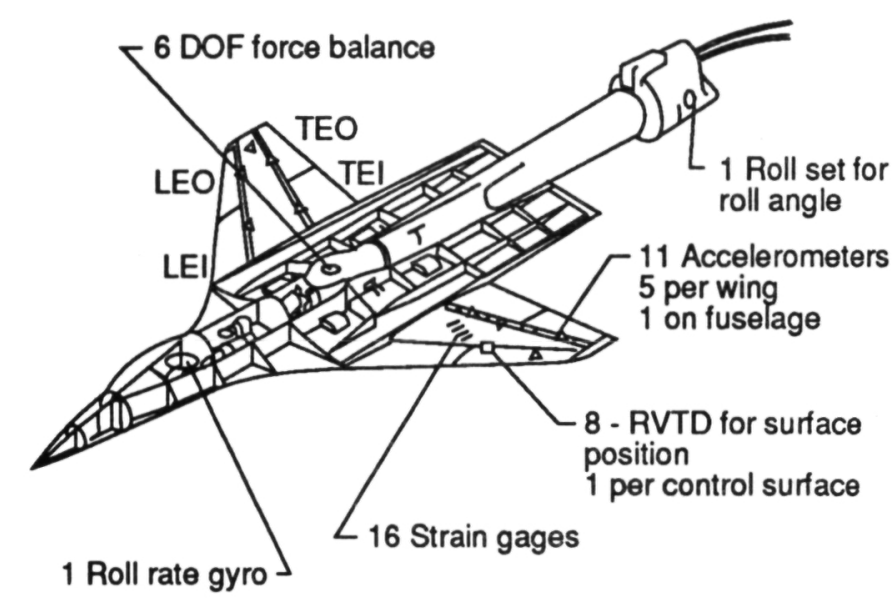

Figure 2. - Wind-tunnel model instrumentation.

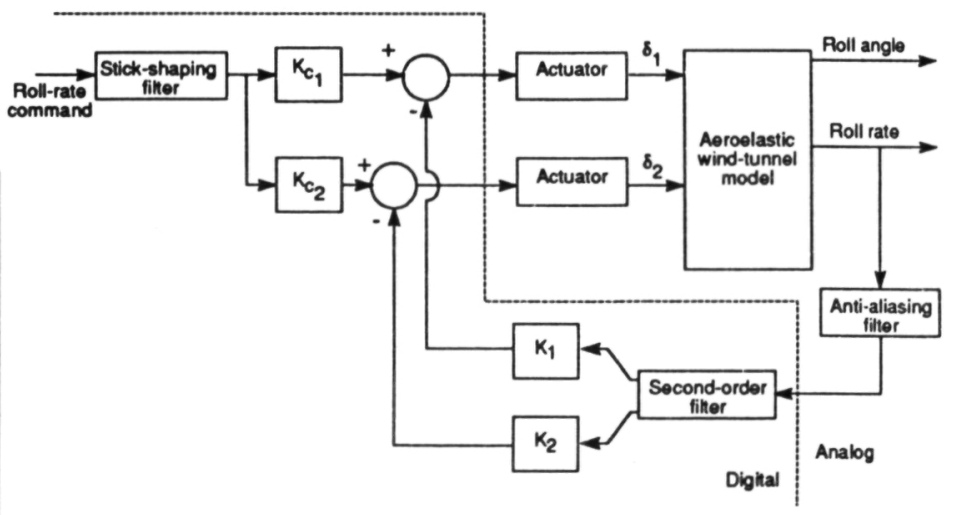

Figure 3. - Block diagram of active roll control system. 


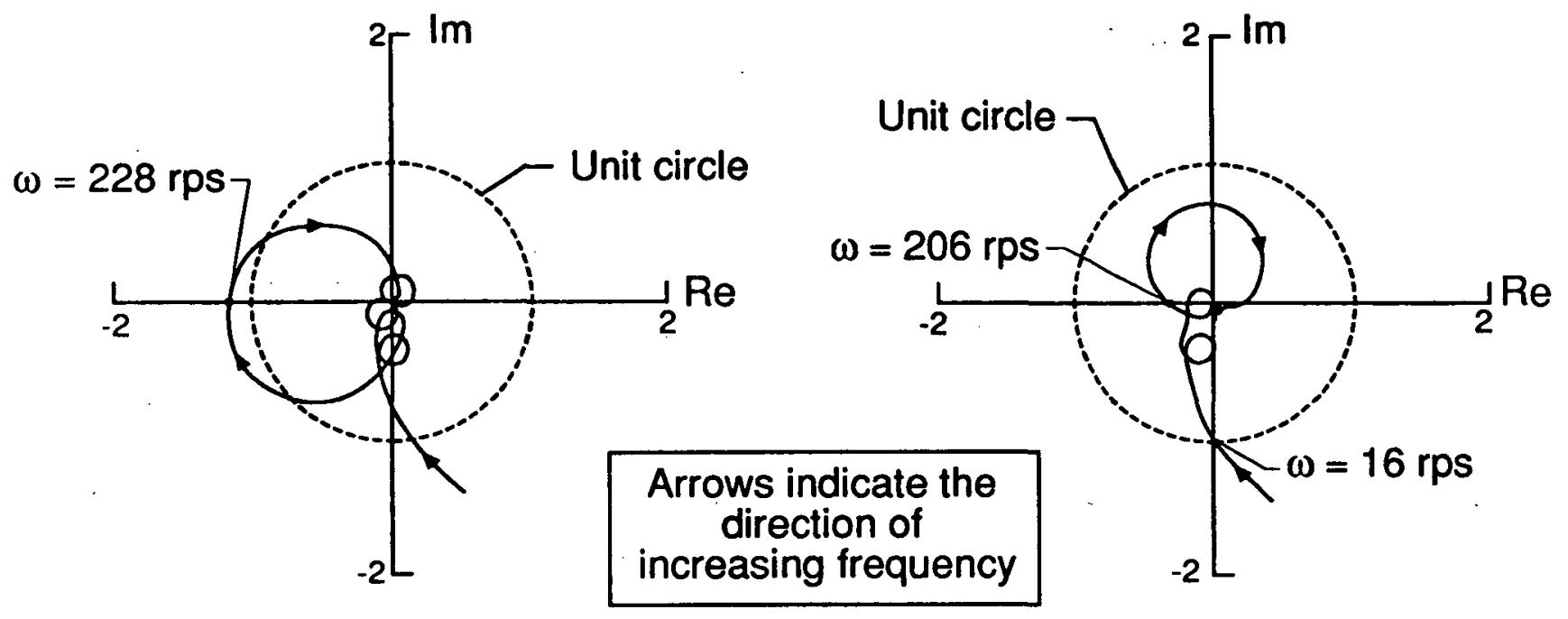

(a) Without second-order filter (unstable)

(b) With second-order filter (stable)

Figure 4. - Effect of second-order filter on Nyquist plots. Mach $=1.15$; dynamic pressure $=250 \mathrm{psf}$.

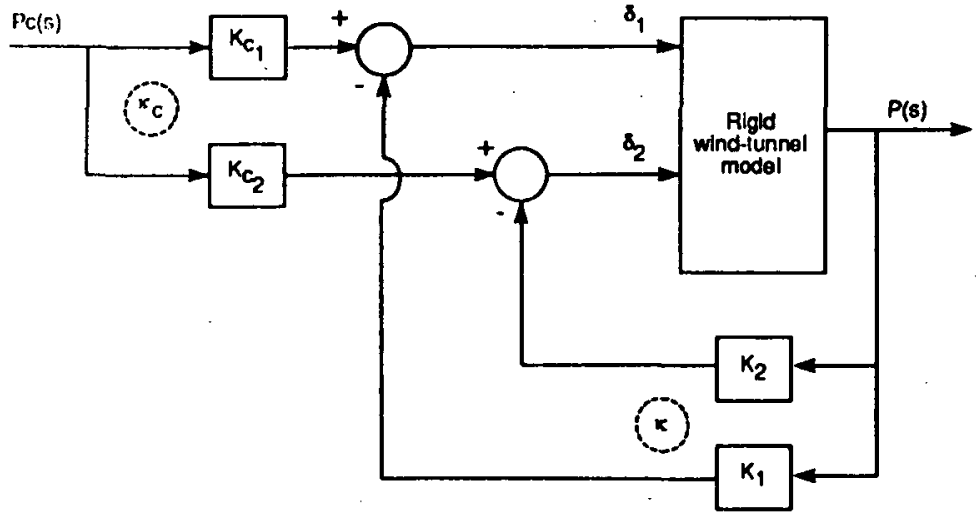

Figurc 5. - Simplified block diagram of active roll control system.

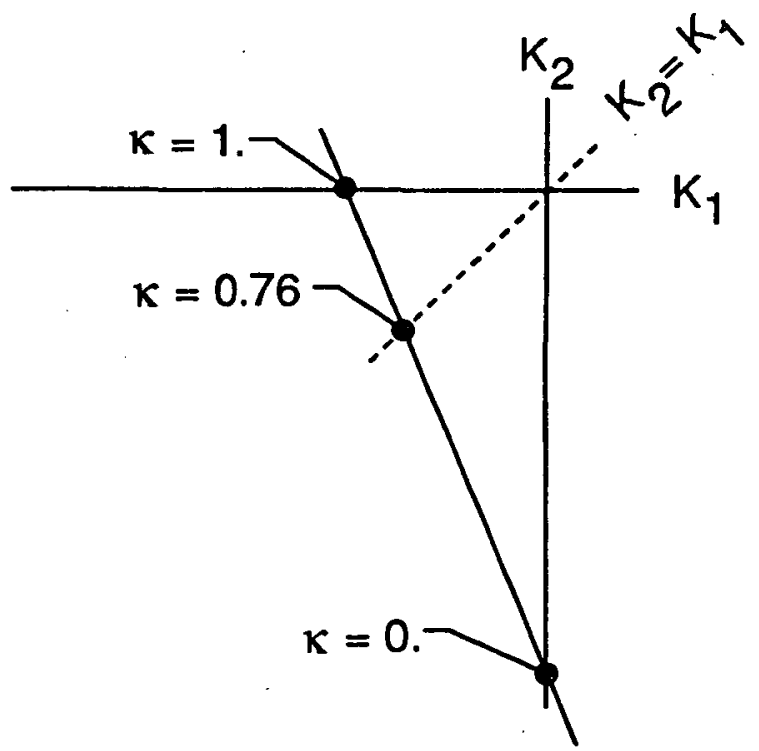

Figure 6. - Fcedback gains which result in constant closed-loop stability. 


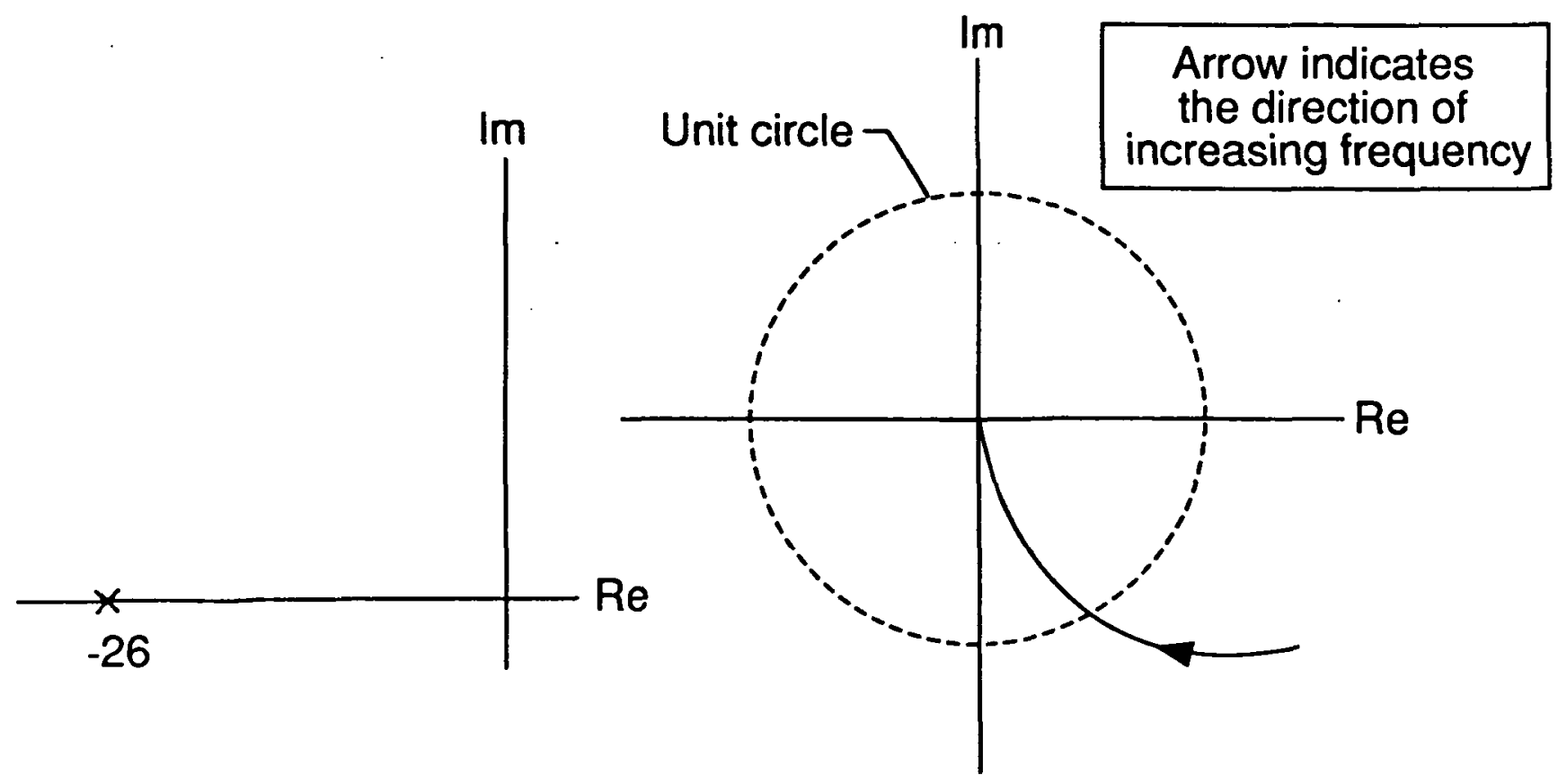

(a) Eigenvalue

(b) Nyquist plot

Figure 7. - Closed-lonp eigenvalue and associated Nyquist plot for constant closed-loopstability.

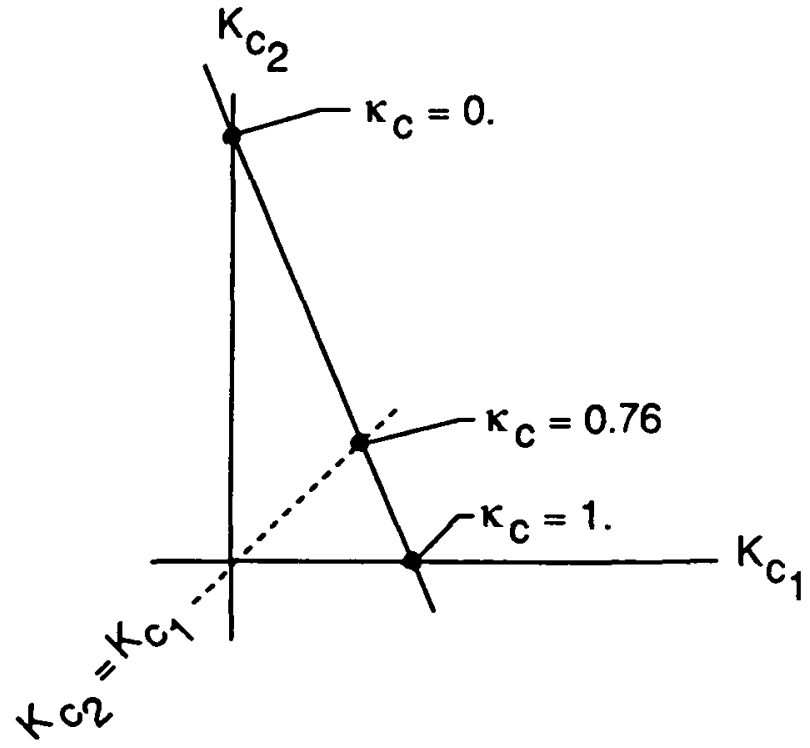

Figure 8. - Forward-path gains which result in constant closed-loop roll performance. 


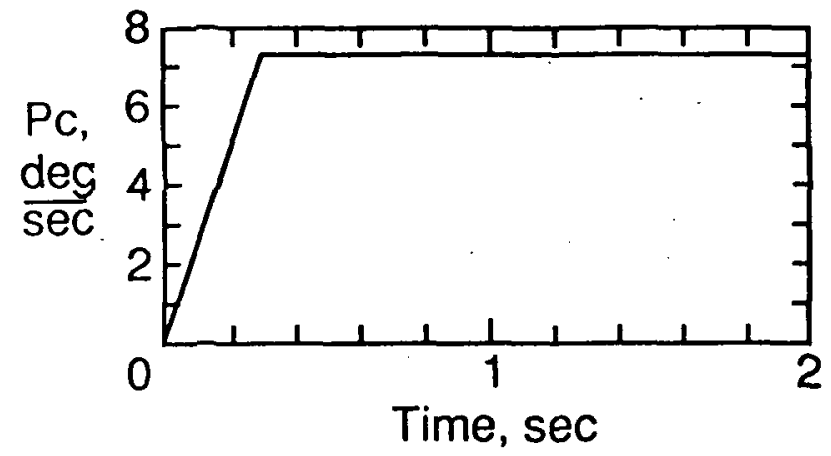

(a) Roll-rate command

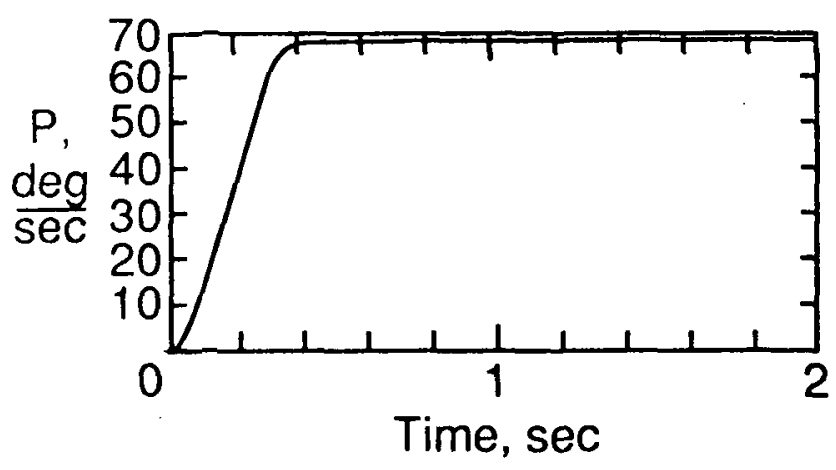

(b) Roll-rate response

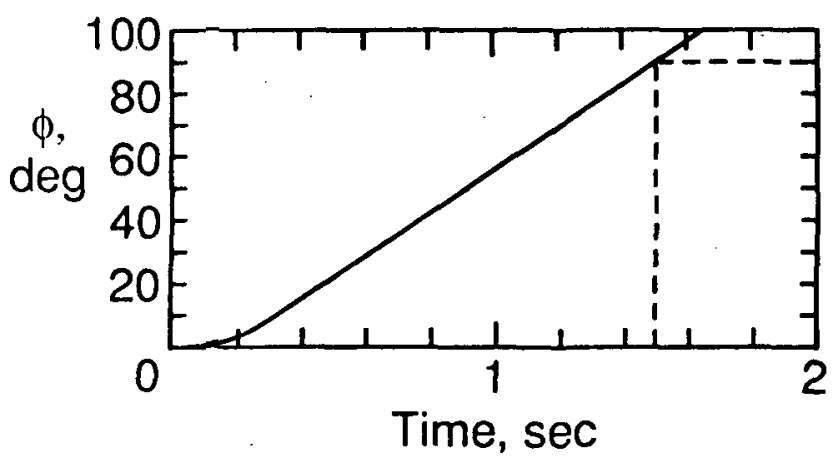

(c) Roll-angle response

Figure 9. - Ramp-hold command and constant-loop roll performance.

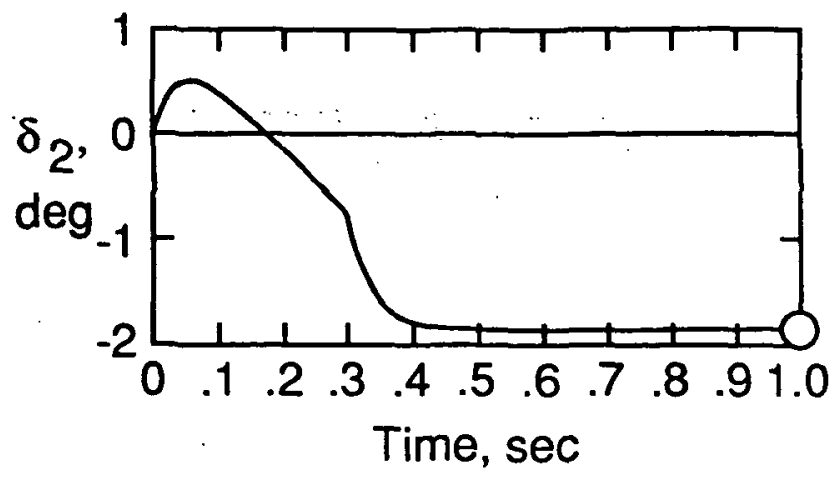

(a) $\kappa=0.56$

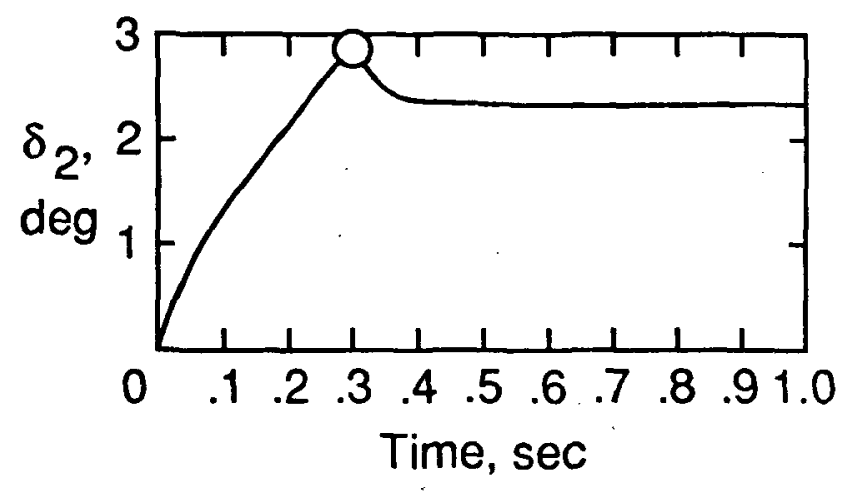

(b) $x=0.76$

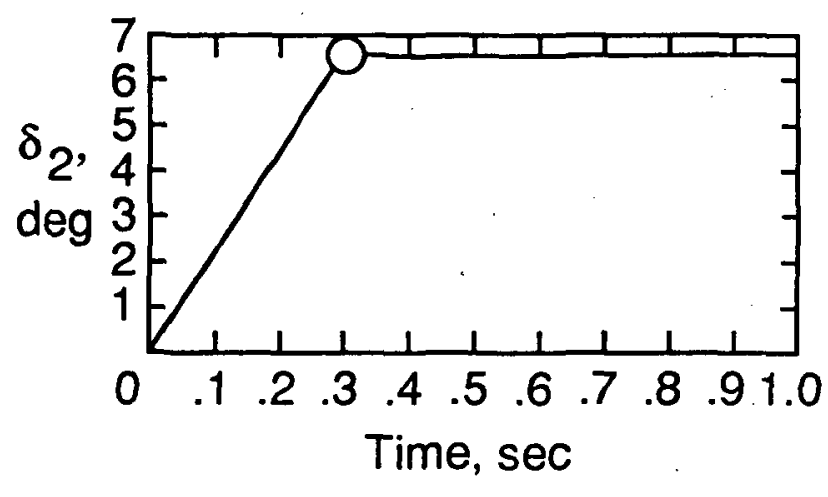

(c) $\kappa=0.96$

Figure 10. - Time histories of Surface 2 (LEO) deflections as a function of $k$. $k_{c}=0.76$. 


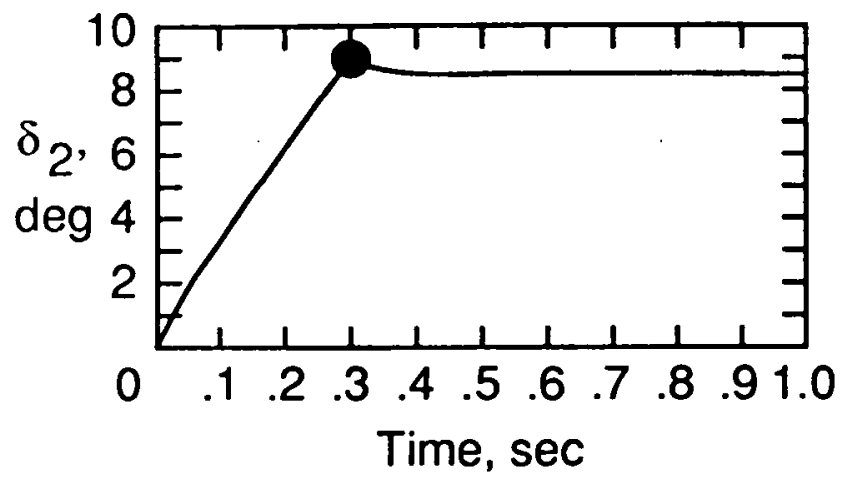

(a) $\kappa_{c}=0.56$

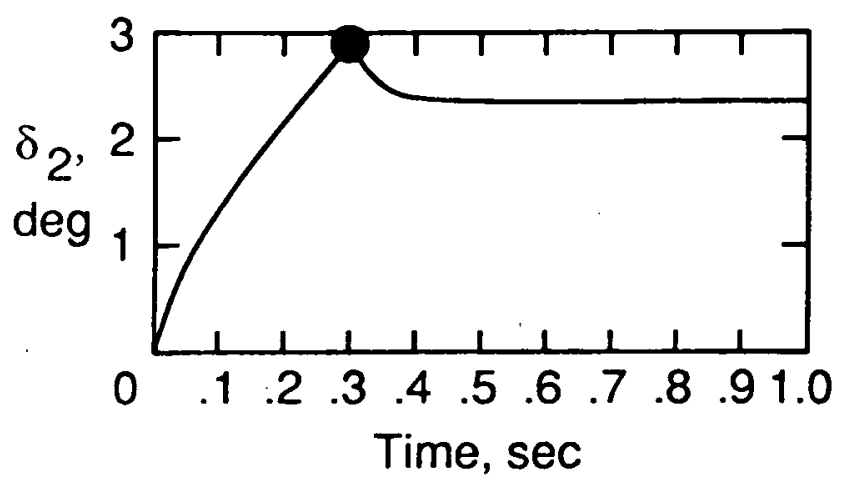

(b) $\kappa_{c}=0.76$

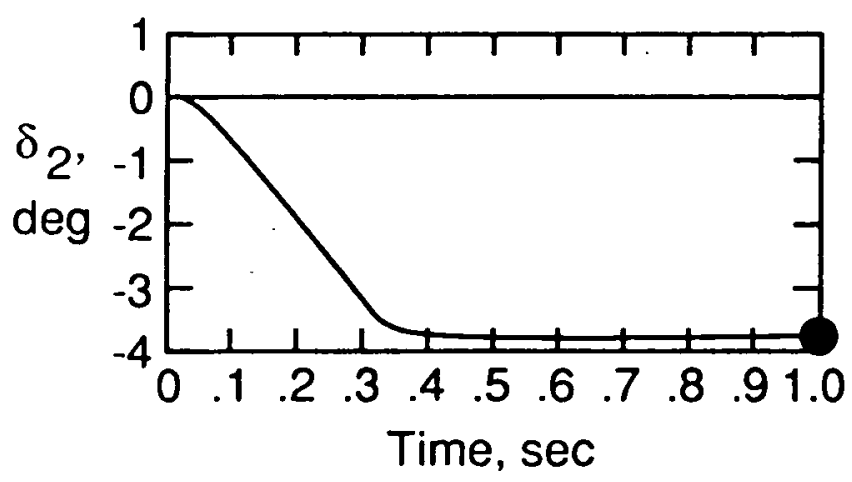

(c) $\kappa_{c}=0.96$

Figurc 11. - Time historics of Surface 2 (LEO) deflections as a function of $\kappa_{c} \kappa=0.76$.

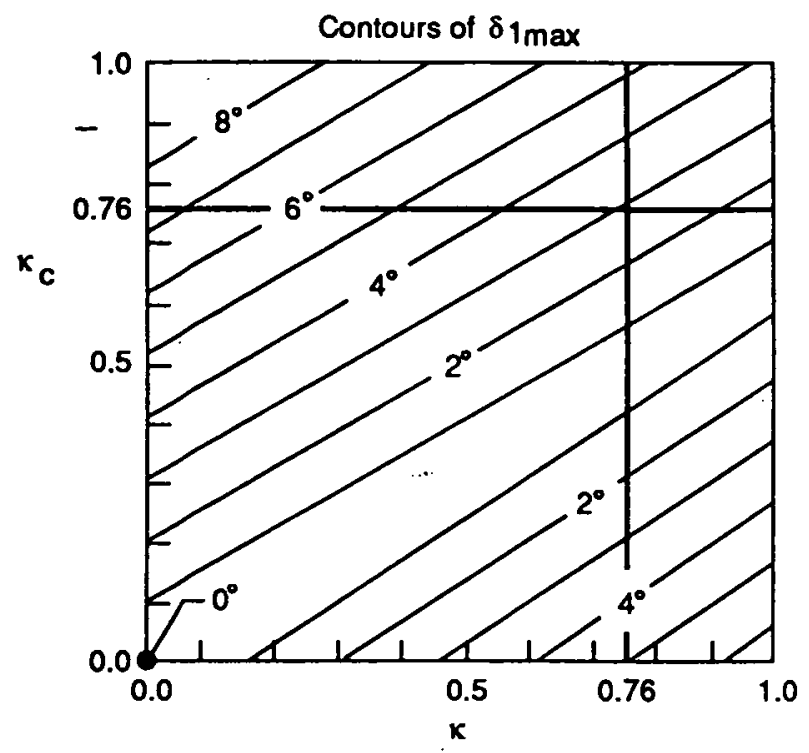

(a) Surface 1 (TEI)

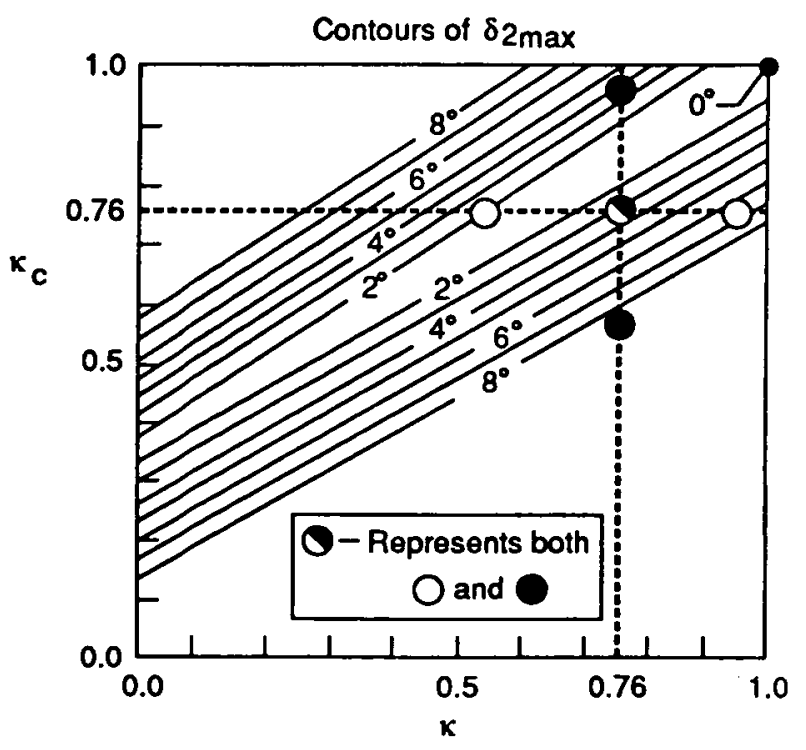

(b) Surface 2 (LEO)

Figure 12. - Contour plots of the absolute valucs of the maximum deflections of surfaces 1 and 2 . 


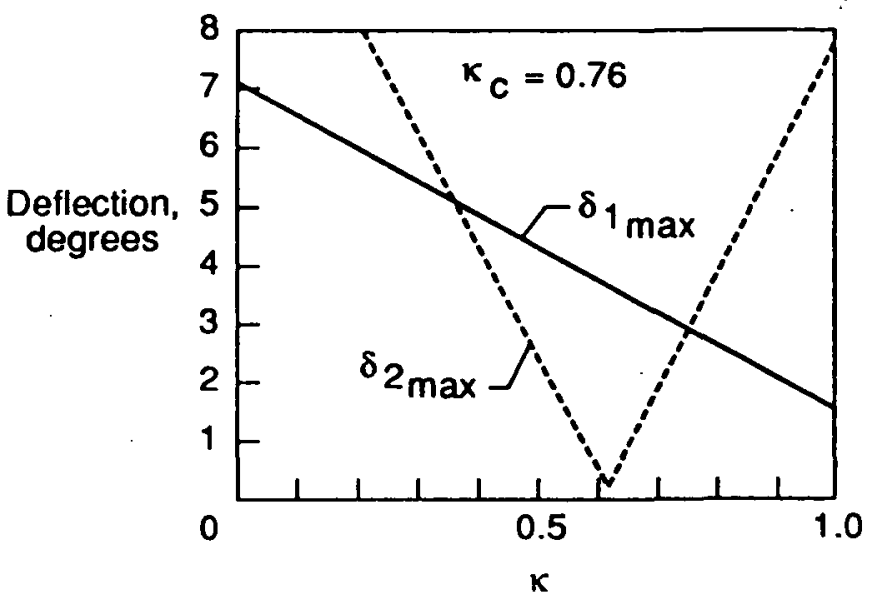

Figure 13. - "Slices" through contour plots for constant $\mathrm{K}_{\mathrm{c}}$

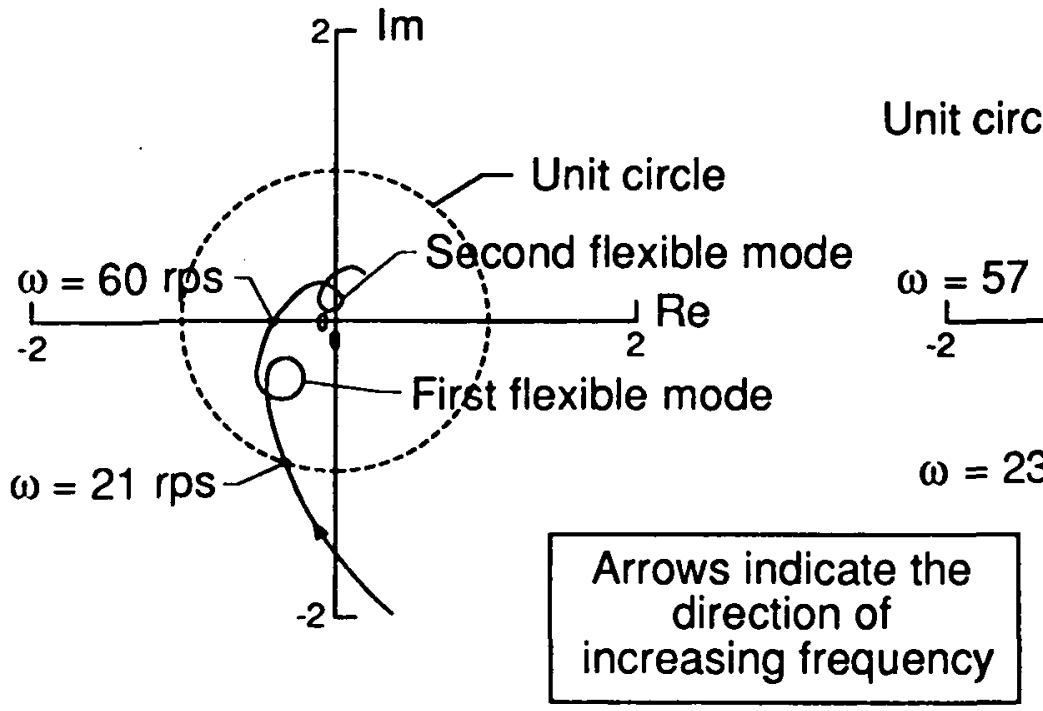

(a) Analysis

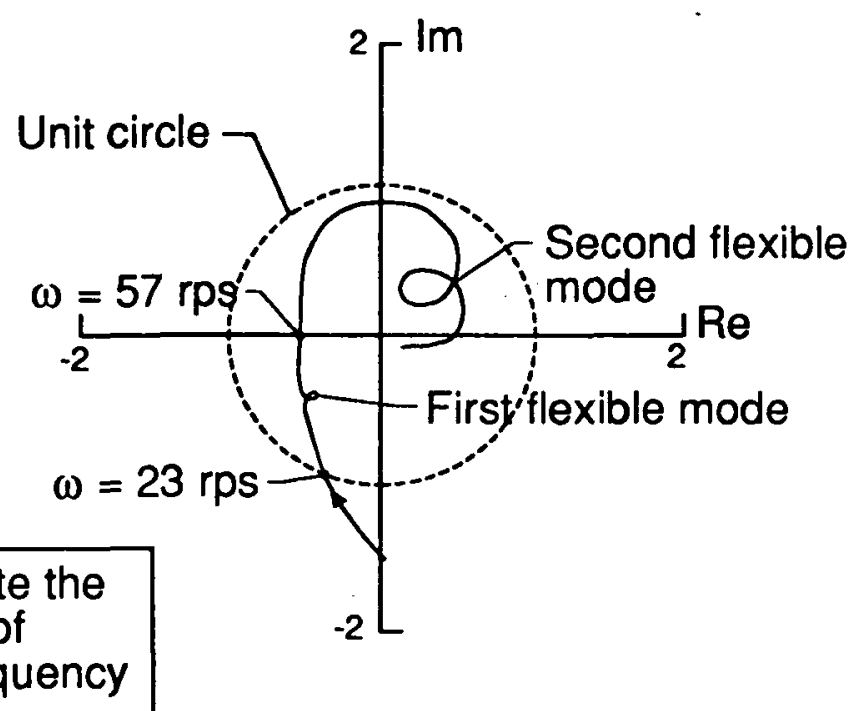

(b) Experiment

Figure 14. - Comparison of analytical and experimental Nyquist plots. Nominal control law; Mach $=0.9$; dynamic pressure $=150 \mathrm{psf}$. 


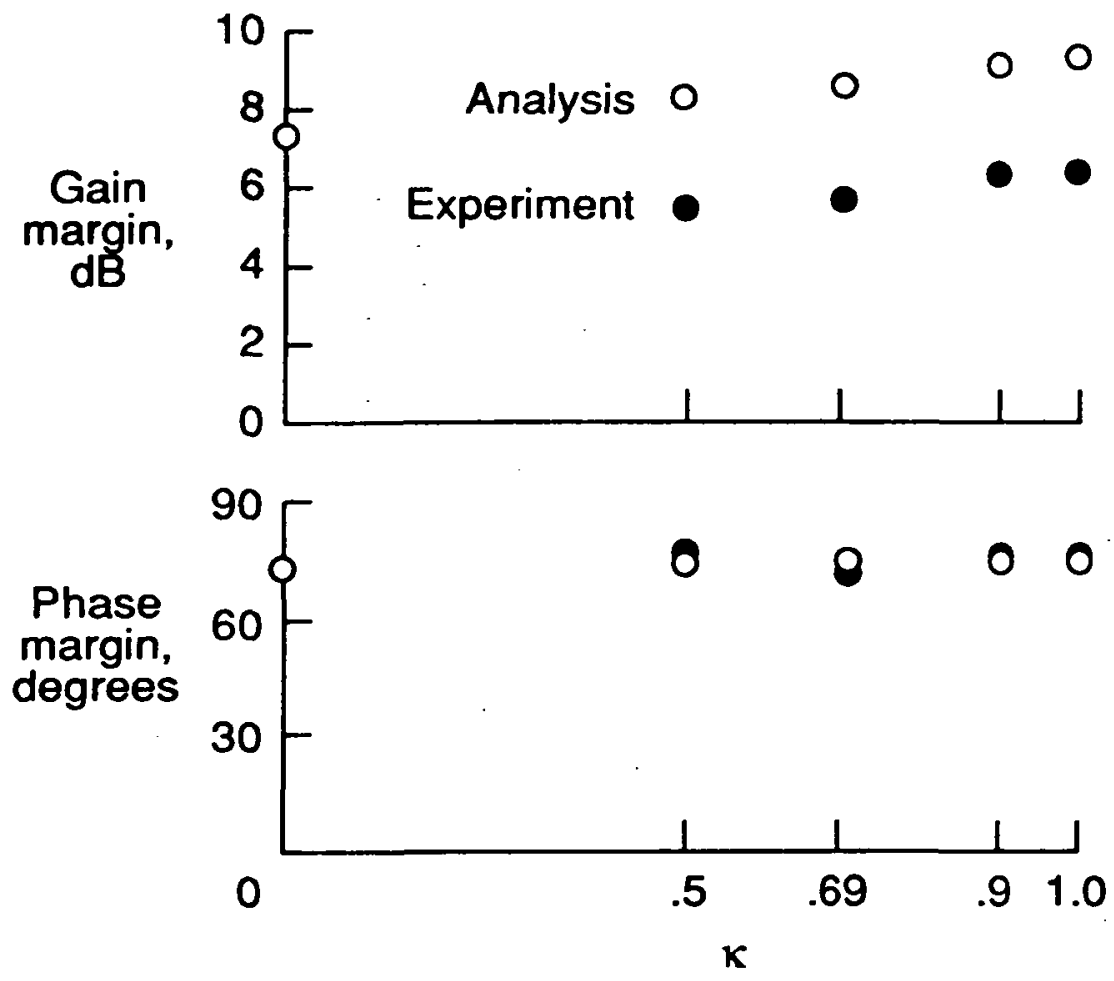

Figure 15. - Comparison of analytical and experimental gain and phase margins as functions of $\mathrm{K}$. Mach $=0.9$; dynamic pressure $=150 \mathrm{psf}$.

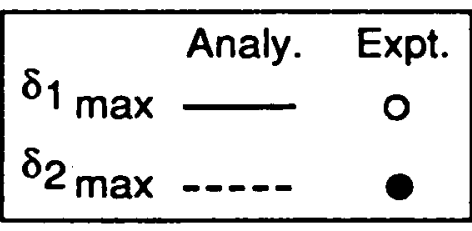

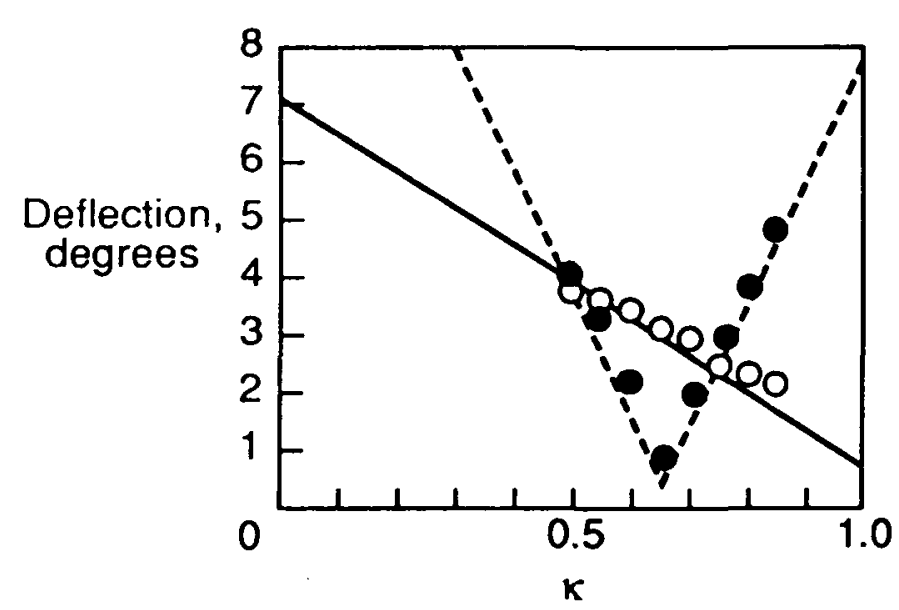

(a) $\kappa$ variation $\kappa_{C}=0.76$

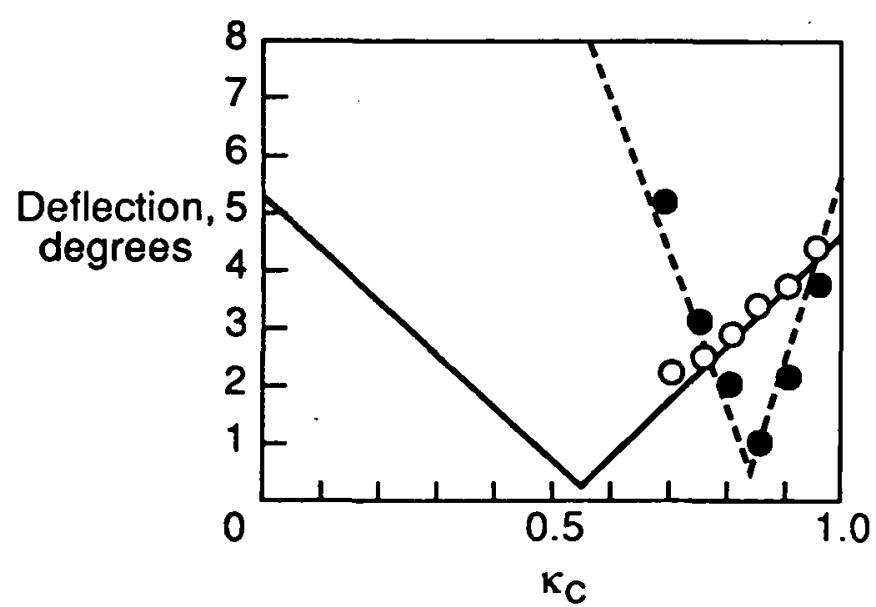

(b) $\kappa_{C}$ variation

$$
\kappa=0.76
$$

Figure 16. - Comparison of analytical and experimental parameterization results. $M a c h=0.9$; dynamic pressure $=250 \mathrm{psf}$. 


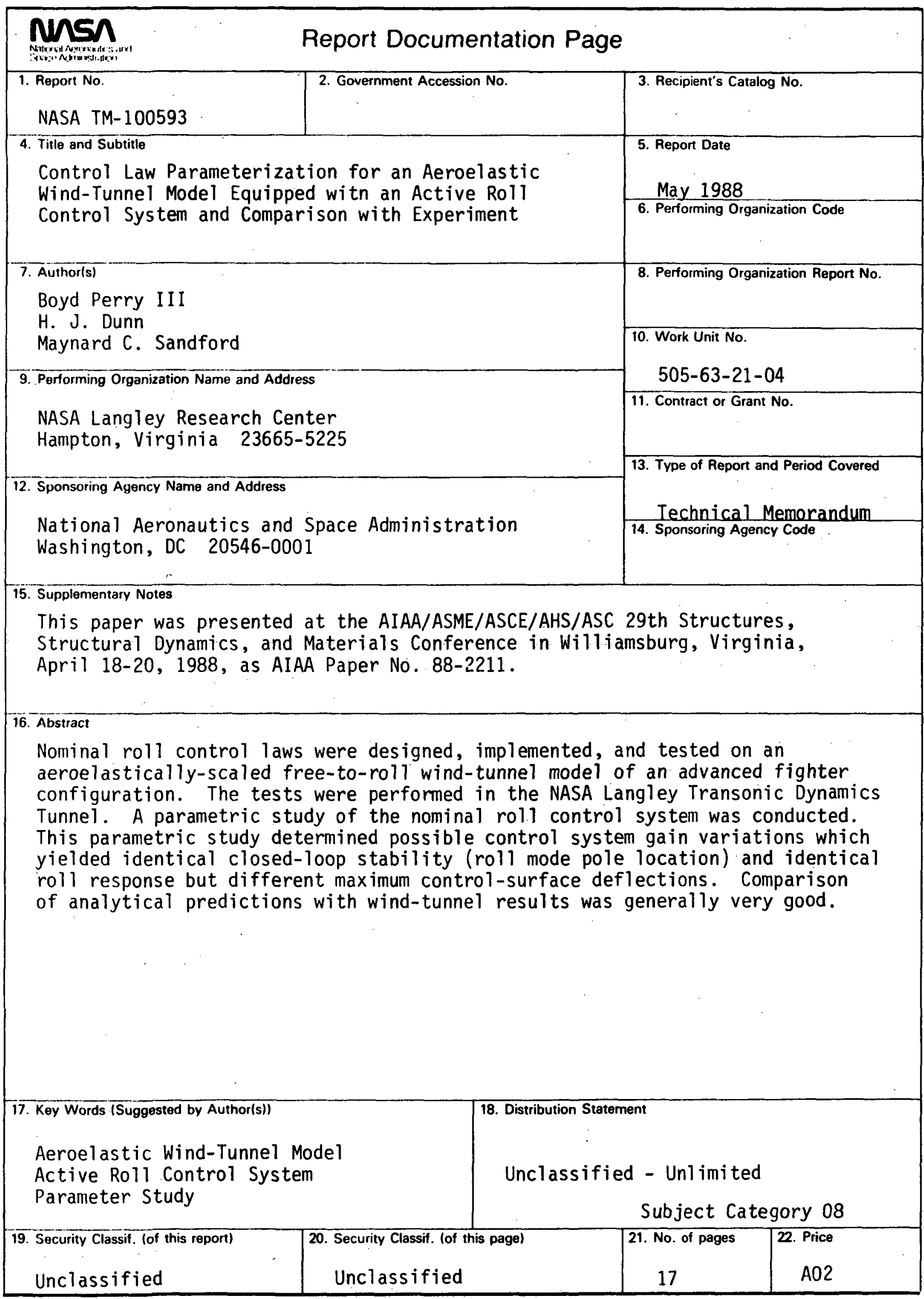

